\title{
Direct radiative effect of carbonaceous aerosols from crop residue burning during the summer harvest season in East China
}

Huan Yao et al.

Correspondence to: Yu Song (songyu@pku.edu.cn)

The copyright of individual parts of the supplement might differ from the CC-BY 3.0 licence. 


\section{Table Captions}

Table S1. Descriptions of the sensitivity test simulations

Table S2. The OA DRE due to absorption at the top of atmosphere (TOA) for the sensitivity test simulations. 
Table S1. Descriptions of the sensitivity test simulations.

\begin{tabular}{|c|c|c|c|c|}
\hline Simulation & Emission inventory & BC-to-OC ratio & OA absorptivity & Mixing state \\
\hline K1.5_BASE & Comprehensive & 0.27 & $k_{O A}{ }^{*} \times 1.5$ & Core-shell \\
\hline K1.5_nOACB & No OA emissions from crop residue burning & 0.27 & $k_{O A}{ }^{*} \times 1.5$ & Core-shell \\
\hline R0.18_BASE & Comprehensive & 0.18 & Saleh et al. (2014) & Core-shell \\
\hline R0.18_nOACB & No OA emissions from crop residue burning & 0.18 & Saleh et al. (2014) & Core-shell \\
\hline R0.18_nOAABS & Comprehensive & 0.18 & None & Core-shell \\
\hline R0.18_nOACB_nOAABS & No OA emissions from crop residue burning & 0.18 & None & Core-shell \\
\hline R0.42_BASE & Comprehensive & 0.42 & Saleh et al. (2014) & Core-shell \\
\hline R0.42_nOACB & No OA emissions from crop residue burning & 0.42 & Saleh et al. (2014) & Core-shell \\
\hline R0.42_nOAABS & Comprehensive & 0.42 & None & Core-shell \\
\hline R0.42_nOACB_nOAABS & No OA emissions from crop residue burning & 0.42 & None & Core-shell \\
\hline VM_BASE & Comprehensive & 0.27 & Saleh et al. (2014) & Volume mixing \\
\hline VM_nCB & No crop residue burning emissions & 0.27 & Saleh et al. (2014) & Volume mixing \\
\hline
\end{tabular}

${k_{\mathrm{OA}}}^{*}$ : the imaginary part of OA's refractive index, see Eq. (2), (3) and (4) (Saleh et al. 2014). 
Table S2. The OA DRE due to absorption at the top of atmosphere (TOA) for the sensitivity test simulations.

\begin{tabular}{|c|c|c|c|}
\hline Testing item & Value & Calculating procedure & $\begin{array}{l}\text { DRE of OA absorption } \\
\left(\mathrm{W} \mathrm{m}^{-2}\right)\end{array}$ \\
\hline OA absorptivity & $k_{O A}{ }^{*} \times 1.5$ & $\left(\mathrm{ADRE}_{\mathrm{K} 1.5 \_\mathrm{BASE}}^{a}-\mathrm{ADRE}_{\mathrm{nOAABS}}\right)-\left(\mathrm{ADRE}_{\mathrm{K} 1.5 \_ \text {nOACB }}-\mathrm{ADRE}_{\mathrm{nOACB} \_n O A A B S}\right)$ & +0.27 \\
\hline \multirow{2}{*}{$\mathrm{BC}$-to-OC ratio } & 0.18 & $\left(\mathrm{ADRE}_{\mathrm{R} 0.18 \_\mathrm{BASE}}-\mathrm{ADRE}_{\mathrm{R} 0.18 \_n O A A B S}\right)-\left(\mathrm{ADRE}_{\mathrm{R} 0.18 \_n O A C B}-\mathrm{ADRE}_{\mathrm{R} 0.18 \_n O A C B \_n O A A B S}\right)$ & +0.33 \\
\hline & 0.42 & $\left(\mathrm{ADRE}_{\mathrm{R} 0.42 \_ \text {BASE }}-\mathrm{ADRE}_{\mathrm{R} 0.42 \_n O A A B S}\right)-\left(\mathrm{ADRE}_{\mathrm{R} 0.42_{-} \text {nOACB }}-\mathrm{ADRE}_{\mathrm{R} 0.42 \_n O A C B \_n O A A B S}\right)$ & +0.13 \\
\hline Mixing State & $\begin{array}{l}\text { Volume } \\
\text { mixing }\end{array}$ & $\mathrm{ADRE}_{\mathrm{VM} \_ \text {BASE }}-\mathrm{ADRE}_{\mathrm{VM} \_n C B}$ & +0.23 \\
\hline
\end{tabular}

${ }^{a}$ The DRE of all the aerosol species (ADRE) at TOA, see Eq. (1) 


\section{Figure Captions}

Figure S1. The diurnal profile of crop-burning emissions in East China.

Figure S2. Time series of the (a) temperature and (b) relative humidity at $2 \mathrm{~m}$ above ground surface (T2 and $\mathrm{RH} 2$, respectively) and the (c) wind speed at $10 \mathrm{~m}$ above ground (WS10) observations (black dot) versus the corresponding WRF-Chem simulations (blue line) at three typical sites (Mengcheng, Suxian, and Xuzhou) in Eastern China in June 2013.

Figure S3. Time series of the observed (dots) and simulated (line) (a) $\mathrm{PM}_{2.5}$, (b) sulfate, (c) ammonium and (d) nitrate mass concentrations $\left(\mu \mathrm{g} / \mathrm{m}^{3}\right)$ at the Suixi site.

Figure S4. Scatterplots of simulated hourly AOD and corresponding MODIS AOD at 23 sites in June 2013. Normalized mean bias (NMB) and the correlation coefficient (R) are given in the scatterplot. 


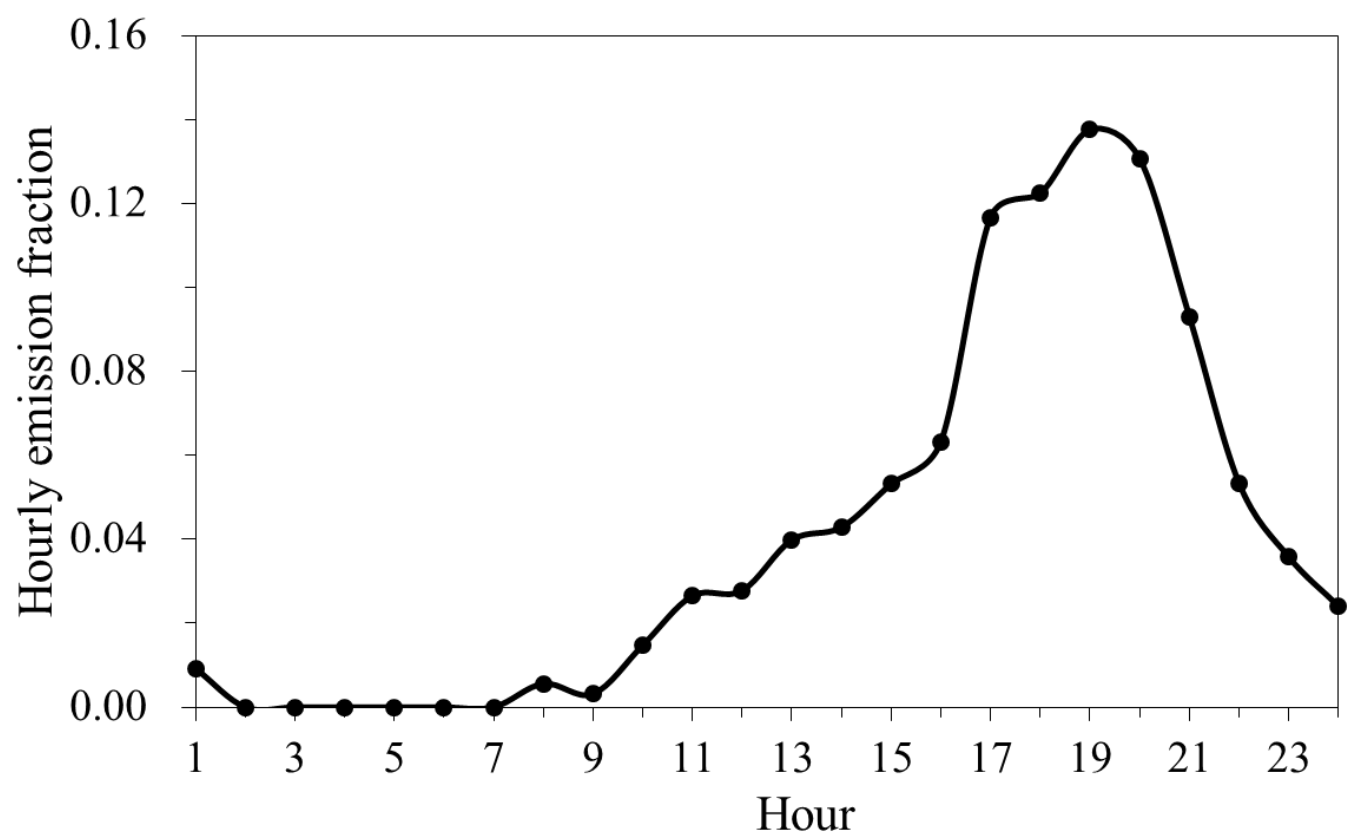

Figure S1. The diurnal profile of crop-burning emissions in East China. The diurnal profile was derived from the results of household surveys in the countryside of East China in the summer of 2013. Face-to-face surveys were made in five counties (Dongping, Lixin, Shangqiu, Xiantao and Dongping) in four Provinces (Shandong, Anhui, Hubei and Henan), where crop residue burning was intensive. Through interviews with about 1500 farmer families, information on farming method including in-field crop burning was collected. The frequencies of firing time and fire durations were calculated for the diurnal profile of crop-burning emissions. The crop fires were also recorded during the observations at Suixi. 
(a)
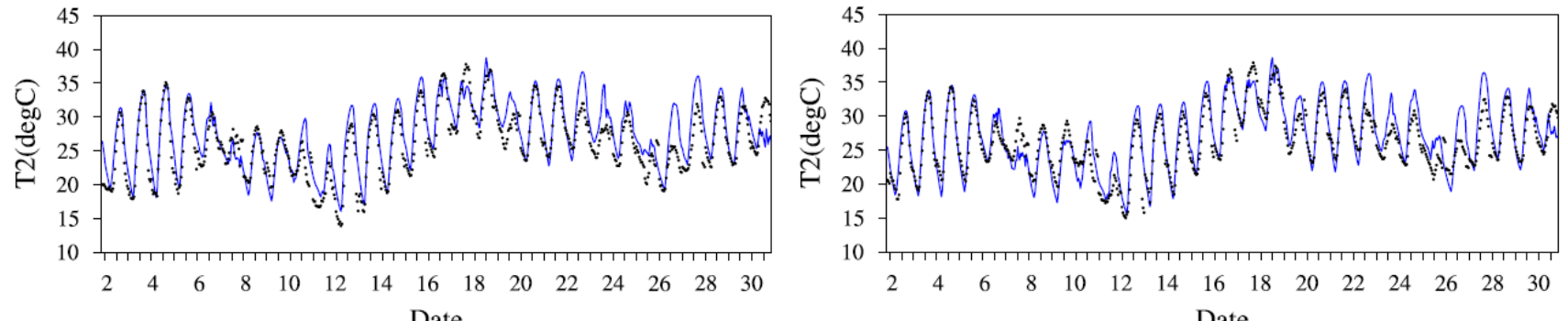

Date

(b)

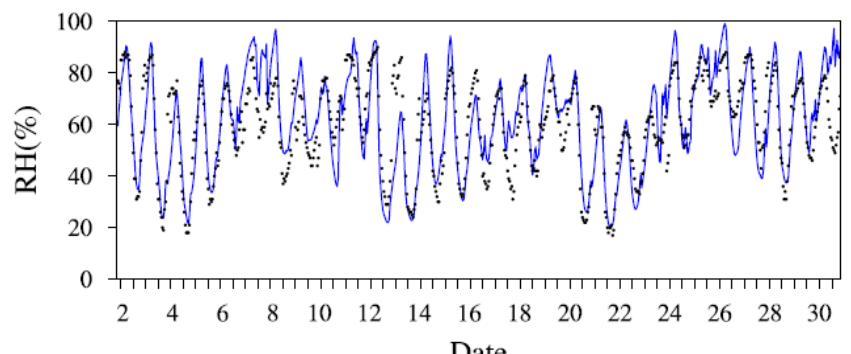

Date

(c)

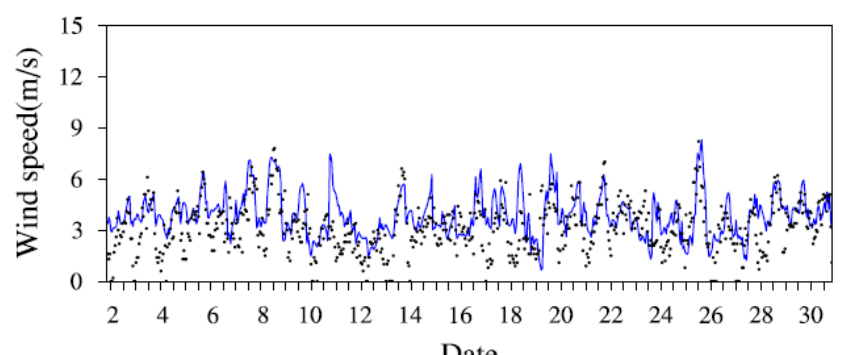

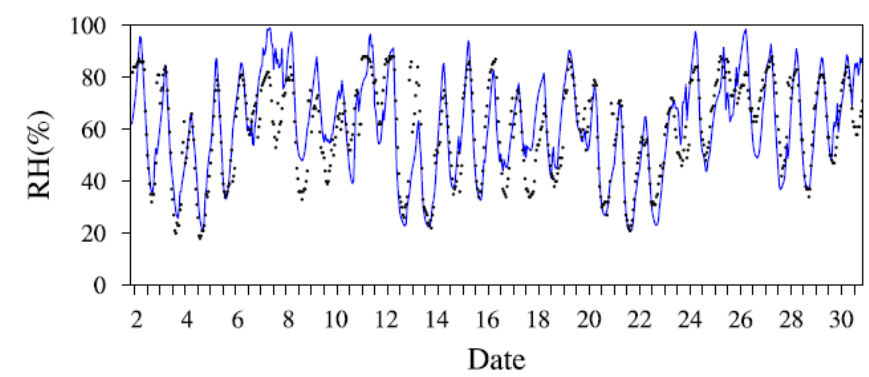

Date

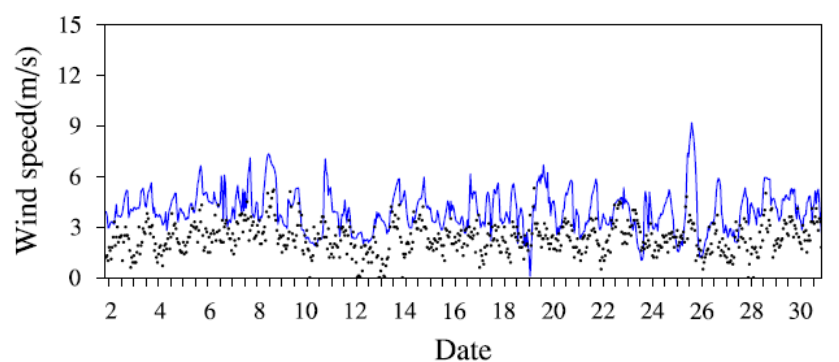

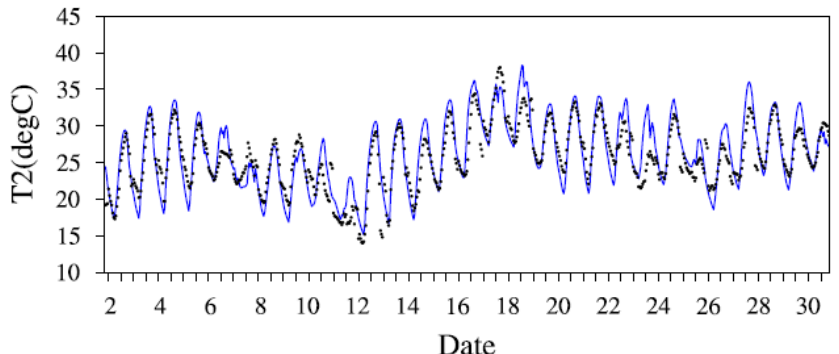
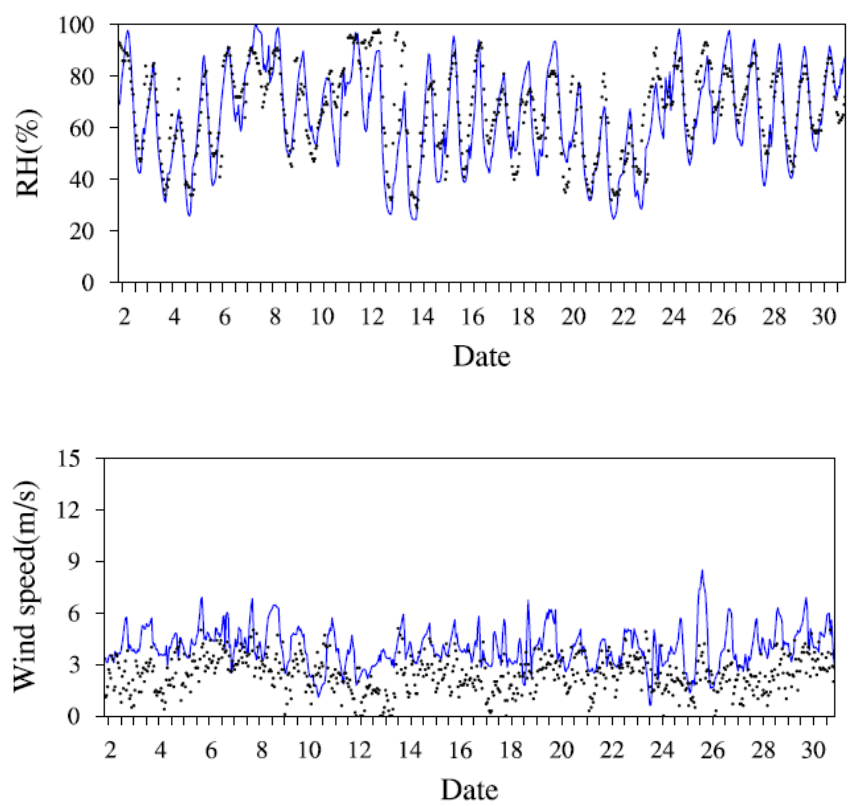

Figure S2. Time series of the (a) temperature and (b) relative humidity at $2 \mathrm{~m}$ above ground surface (T2 and RH2, respectively) and the (c) wind speed at $10 \mathrm{~m}$ above ground (WS10) observations (black dot) versus the corresponding WRF-Chem simulations (blue line) at three typical sites (Mengcheng, Suxian, and Xuzhou) in Eastern China in June 2013. 

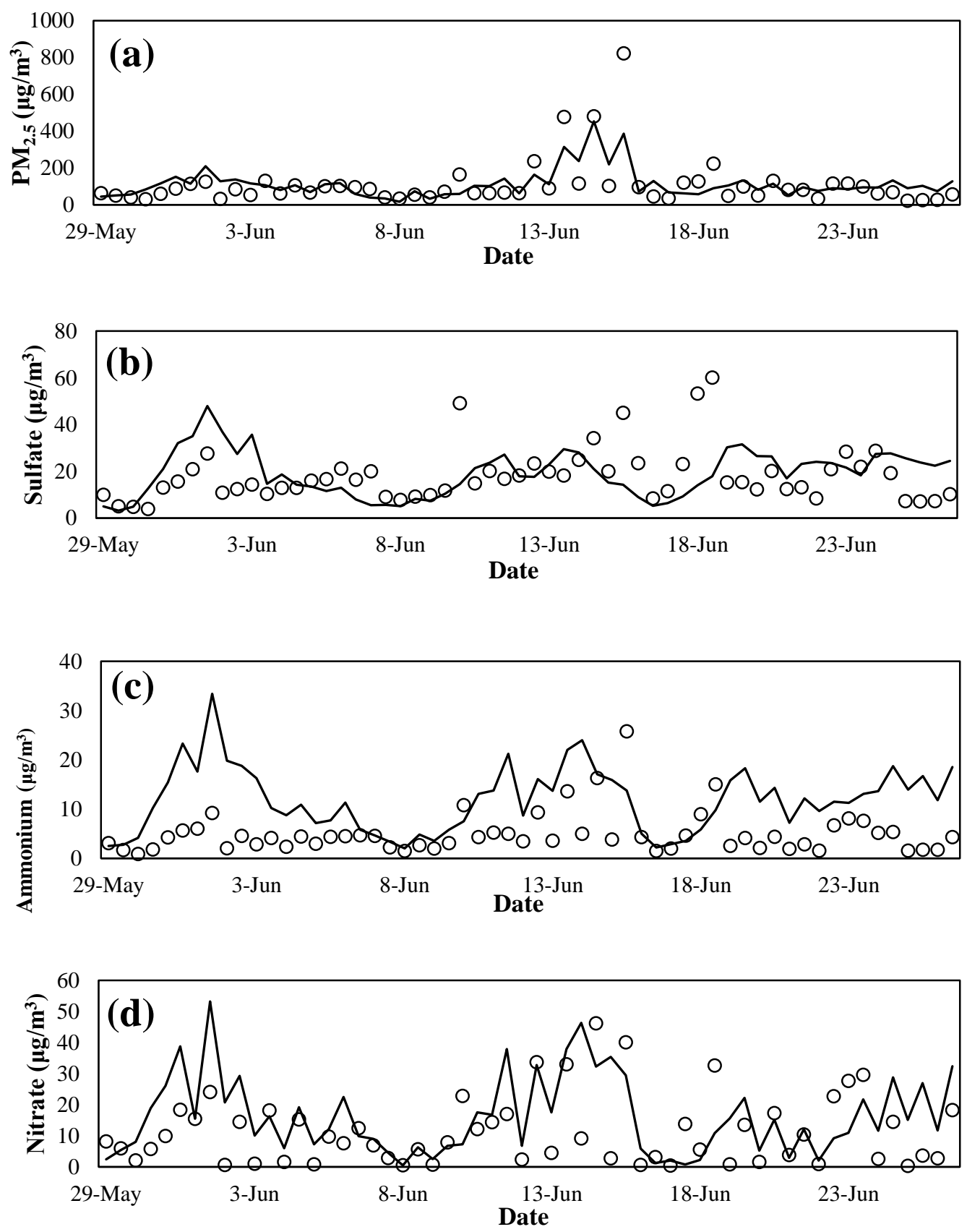

Figure S3. Time series of the observed (dots) and simulated (line) (a) $\mathrm{PM}_{2.5}$, (b) sulfate,

(c) ammonium and (d) nitrate mass concentrations $\left(\mu \mathrm{g} / \mathrm{m}^{3}\right)$ at the Suixi site. 


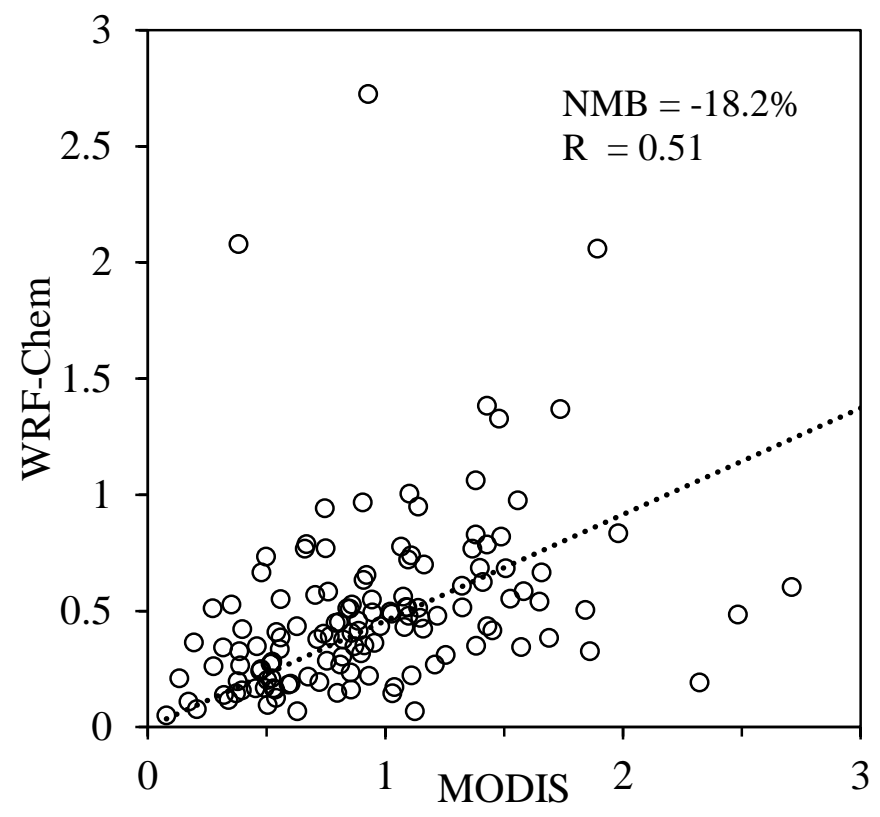

Figure S4. Scatterplots of simulated hourly AOD and corresponding MODIS AOD at 23 sites in June 2013. Normalized mean bias (NMB) and the correlation coefficient (R) are given in the scatterplot. 